\title{
Ground Penetrating Radar in Hydrogeophysics
}

\author{
Sébastien Lambot, ${ }^{*}$ Andrew Binley, Evert Slob, and Susan Hubbard
}

$\mathrm{T}$ o meet the needs of a growing population and to provide us with a higher quality of life, increasing pressures are being placed on our environment through the development of agriculture, industry, and infrastructures. Soil erosion, groundwater depletion, salinization, and pollution have been recognized for decades as major threats to ecosystems and human health. More recently, the progressive substitution of fossil fuels by biofuels for energy production and climate change have been recognized as potential threats to our water resources and sustained agricultural productivity.

The vadose zone mediates many of the processes that govern water resources and quality, such as the partition of precipitation into infiltration and runoff, groundwater recharge, contaminant transport, plant growth, evaporation, and energy exchanges between the Earth's surface and its atmosphere. It also determines soil organic carbon sequestration and carbon-cycle feedbacks, which could substantially impact climate change. The vadose zone's inherent spatial variability and inaccessibility precludes direct observation of the important subsurface processes. In a societal context where the development of sustainable and optimal environmental management strategies has become a priority, there is a strong prerequisite for the development of noninvasive characterization and monitoring techniques of the vadose zone. In particular, hydrogeophysical approaches applied at relevant scales are required to appraise dynamic subsurface phenomena and to develop optimal sustainability, exploitation, and remediation strategies.

Among existing geophysical techniques, ground penetrating radar (GPR) technology is of particular interest for providing high-resolution subsurface images and specifically addressing water-related questions. Ground penetrating radar is based on the transmission and reception of VHF-UHF (30-3000 MHz) electromagnetic waves into the ground, whose propagation is determined by the soil electromagnetic properties and their spatial distribution. As the dielectric permittivity of water overwhelms the permittivity of other soil components, the presence of water in the soil principally governs GPR wave propagation. Therefore, GPR-derived dielectric permittivity is usually used as surrogate measure for soil water content. In the areas of unsaturated zone hydrology and water resources, GPR has been used to identify soil stratigraphy, to locate water tables, to follow wetting front movement, to estimate soil water content, to assist in subsurface hydraulic parameter identification, to assess soil salinity, and to support the monitoring of contaminants.

The purpose of this special section of the Vadose Zone Journal is to present recent research advances and applications of GPR in hydrogeophysics, with a particular emphasis on vadose zone investigations. This special section includes contributions presented at the European Geosciences Union General Assembly 2006 (EGU 2006, Vienna, Austria) and the 11th International Conference on Ground Penetrating Radar (GPR 2006, Columbus, OH). The studies presented here deal with a wide range of surface and borehole GPR applications, including GPR sensitivity to contaminant plumes, new methods for soil water content determination, three-dimensional imaging of the subsurface, time-lapse monitoring of hydrodynamic events and inversion techniques for soil hydraulic properties estimation, and joint interpretation of GPR and electric resistivity tomography (ERT) data.

The first part of this special section deals with surface-based GPR applications. Because surface-based datasets can typically be acquired quite rapidly, they are attractive for providing information about subsurface variability

Abbreviations: ERT, electric resistivity tomography; FDTD, finite-difference time-domain; GPR, ground penetrating radar. 
over field-relevant scales. Ground penetrating radar profiles have been used for decades to provide images of dielectric permittivity contrasts, which are in turn commonly used to infer variations in subsurface geological units. As illustrated by papers in the first part of this special section, recent advances in petrophysics, processing, inversion, and estimation approaches illustrate how surface-based GPR methods can also be useful for providing quantitative information about subsurface properties and processes. Using three-dimensional finite-difference time-domain (FDTD) simulations and dielectric material property mixing models, Cassidy (2008) analyzes the nature and spectral content of GPR signal attenuation and scattering within the vadose zone of a coastal, mature light nonaqueous phase liquid contaminated site to improve understanding of the contamination plume. In particular, he shows how different contaminant mixtures can affect the radar signal. Soldovieri et al. (2008) present a new tomographic approach for estimating soil dielectric permittivity and correlated water content from constant-offset surface GPR data acquired above a buried object. The proposed inverse scattering method relies on the determination of the best focusing of the reflecting object in the radar image. Their approach offers several advantages compared to traditional methods based on reflecting hyperbola determination, for which uncertainty may be relatively large. For the case of homogeneous media, Oden et al. (2008) propose a method for determining soil surface water content by means of an inversion algorithm that minimizes the difference between modeled and recorded attributes of a single radar trace. The forward model consists of a catalog of antenna responses for a full range of soil electric properties and antenna heights, which can be constructed using FDTD modeling or real measurements. Bradford (2008) uses continuous multi-offset surface GPR to investigate vertical and horizontal distributions of soil water content at a contaminated site near a former refinery. He uses reflection tomography together with prestack depth migration to estimate wave propagation velocities in the postmigration domain. This procedure inherently leads to higher spatial resolution and accuracy compared to conventional velocity analysis methods. Goutaland et al. (2008) use GPR to detect depositional units within glaciofluvial quaternary deposits underlying a stormwater infiltration basin, from which a three-dimensional lithofacies distribution model could be derived. Knowledge of the different lithofacies hydraulic properties permitted them to construct a hydrostratigraphic model. Finally, Saintenoy et al. (2008) report on the use of surface GPR to monitor water dynamics in a sandy soil, subject to a point injection at the bottom of a pit. Following the movement of the top and bottom wetting fronts, they found good agreements with estimations provided by a twodimensional hydrodynamic model based on the solution of the Richards equation.

The second part of this special section deals with crossborehole GPR applications, focusing especially on time-lapse monitoring of hydrodynamic events for the estimation of the soil hydraulic and transport properties. Deiana et al. (2008) compare cross-borehole GPR and ERT to monitor a forced water injection experiment in quaternary sand and gravel sediments of the Po River plain in Italy. They use both zero- and multi-offset GPR measurements and straight-ray tomography to reconstruct oneand two-dimensional distributions of soil water content. The soil saturated hydraulic conductivity is estimated from the injected water center of mass by calibrating a hydrodynamic model. For both GPR and ERT, significant mass balance errors with respect to the injected water are observed. Looms et al. (2008b) also jointly use GPR and ERT to monitor both soil water content and electric resistivity during a water and tracer infiltration experiment. Using geophysical attributes available from both methods, the soil solution tracer concentration between the boreholes is estimated, which permits the identification of transport parameters (pore water velocity and dispersivity) using a one-dimensional moment analysis. As with Deiana et al. (2008), significant mass balance errors are also observed. To decrease inherent nonuniqueness in geophysical data inversion for two-dimensional imaging, Looms et al. (2008a) adopt an integrated hydrogeophysical inverse modeling approach whereby the geophysical and hydrodynamic models constrain each other. The method is applied to the datasets presented in Looms et al. (2008b) to estimate the unsaturated soil hydraulic properties. The choice of the velocity distribution covariance model for constraining cross-borehole GPR tomography is the focus of Hansen et al. (2008). They propose a way to quantify the adequacy of the a priori covariance model from the observed radar data. Cordua et al. (2008) emphasize the importance of properly accounting for correlated data errors in the data error covariance matrix of the GPR tomography inverse operator. They show that this may significantly improve velocity estimates. Finally, Farmani et al. (2008) use curved-ray GPR tomography to monitor water content in a ice-contact delta in Norway during a snowmelt event. Their results are in good agreement with surface GPR reflection and neutron meter data and X-ray images of core samples.

The use of GPR in hydrogeophysical studies has known a rapid development over the last decade. New GPR technologies, processing algorithms, and estimation approaches are being continuously developed and integrated with other geophysical or hydrological sources of information to improve subsurface characterization. The research papers herein provide a good overview of the different techniques available and under investigation. These papers also show and discuss the many difficulties encountered in using GPR for estimating vadose zone processes and states. Several challenges must still be overcome before we can benefit from the full potential of GPR for soil characterization. In particular, full-waveform forward and inverse modeling procedures are required to maximize quantitative and qualitative information retrieval capabilities of GPR. Particularly in the area of hydrogeophysics, GPR signal inversion techniques have yet to be integrated in a mechanistic data fusion framework with other sources of information (such as process knowledge) to ensure the well-posedness of the complex inverse problems. Once this is achieved, GPR will be established as a powerful tool to support understanding of the vadose zone hydrological processes and the development of optimal management strategies for our soil and water resources.

\section{References}

Bradford, J.H. 2008. Measuring water content heterogeneity using multifold GPR with reflection tomography. Vadose Zone J. 7:184-193 (this issue).

Cassidy, N.J. 2008. GPR attenuation and scattering in a mature hydrocarbon spill: A modeling study. Vadose Zone J. 7:140-159 (this issue).

Cordua, K.S., M.C. Looms, and L. Nielsen. 2008. Accounting for correlated data errors during inversion of cross-borehole ground penetrating radar data. Vadose Zone J. 7:263-271 (this issue).

Deiana, R., G. Cassiani, A. Villa, A. Bagliani, and V. Bruno. 2008. Calibration of 
a vadose zone model using water injection monitored by GPR and electrical resistance tomography. Vadose Zone J. 7:215-226 (this issue).

Farmani, M.B., H. Keers, and N.O. Kitterød. 2008. Time lapse GPR tomography of unsaturated water flow in an ice-contact delta. Vadose Zone J. 7:272-283 (this issue).

Goutaland, D., T. Winiarski, J.-S. Dubé, G. Bièvre, J.-F. Buoncristiani, M. Chouteau, and B. Giroux. 2008. Hydrostratigraphic characterization of glaciofluvial deposits underlying an infiltration basin using ground penetrating radar. Vadose Zone J. 7:194-207 (this issue).

Hansen, T.M., M.C. Looms, and L. Nielsen. 2008. Inferring the subsurface structural covariance model using cross-borehole ground penetrating radar tomography. Vadose Zone J. 7:249-262 (this issue).

Looms, M.C., A. Binley, K.H. Jensen, L. Nielsen, and T.M. Hansen. 2008a. Identifying unsaturated hydraulic parameters using an integrated data fusion approach on cross-borehole geophysical data. Vadose Zone J. 7:238248 (this issue).

Looms, M.C., K.H. Jensen, A. Binley, and L. Nielsen. 2008b. Monitoring unsaturated flow and transport using cross-borehole geophysical methods. Vadose Zone J. 7:227-237 (this issue).

Oden, C.P., G.R. Olhoeft, D.L. Wright, and M.H. Powers. 2008. Measuring the electrical properties of soil using a calibrated ground-coupled GPR System. Vadose Zone J. 7:171-183 (this issue).

Saintenoy, A., S. Schneider, and P. Tucholka. 2008. Evaluating ground penetrating radar use for water infiltration monitoring. Vadose Zone J. 7:207-214 (this issue).

Soldovieri, F., G. Prisco, and R. Persico. 2008. Application of microwave tomography in hydrogeophysics: Some examples. Vadose Zone J. 7:160-170 (this issue). 